\title{
Turmeric Extracts Containing Curcuminoids Prevent Experimental Rheumatoid Arthritis
}

\author{
Janet L. Funk ${ }^{*,+,}$, Janice N. Oyarzo ${ }^{\dagger, \ddagger}$, Jennifer B. Frye ${ }^{\dagger, *}$, Guanjie Chen ${ }^{\dagger, \S}$, R. \\ Clark Lantz ${ }^{\dagger,}$, Shivanand D. Jolad ${ }^{\dagger, \|}$, Aniko M. Sólyom ${ }^{\dagger, \perp}$, and Barbara N. \\ Timmermann ${ }^{\dagger}, \|$ \\ ${ }^{\dagger}$ Arizona Center for Phytomedicine Research, "Department of Medicine, \\ ${ }^{\S}$ Department of Cell Biology and Anatomy, ${ }^{\perp}$ Department of Pharmacology, \\ University of Arizona, Tucson, AZ 85724 USA, and "I Department of Medicinal \\ Chemistry, School of Pharmacy, University of Kansas, Lawrence, KS 66045 USA

\section{SUPPORTING DATA}

Footnote: Dedicated to Dr. Norman Farnsworth of the University of Illinois at Chicago for his pioneering work on bioactive natural products.

Corresponding Author: Janet L. Funk, MD

Tele: (520) 626-3242

Fax: (520) 626-1106

Email: jfunk@u.arizona.edu 


\section{Figures}

S1. HPLC Chromatograms of (A) crude turmeric methanol extract, (B) essential oildepleted turmeric fraction, and (C) purified curcuminoids (commercial curcumin) demonstrating three curcuminoid peaks common to all extracts and depletion of essential oils in samples (B) and (C). Samples $(10 \mu \mathrm{L})$ were injected onto a Synergy, $4 \mu$, HydroRP 250x4.6 mm column coupled with SecurityGuard AJO-4287 guard column (Phenomenex, Torrance, CA 90501). The mobile phases were (A) $500 \mu \mathrm{L}$ acetic acid/L of Nanopure water and (B) $500 \mu \mathrm{L}$ acetic acid/L of acetonitrile. The eluent was monitored at $425 \mathrm{~nm}, 370 \mathrm{~nm}, 280 \mathrm{~nm}$ and $250 \mathrm{~nm}$; the flow rate was $1 \mathrm{~mL} / \mathrm{min}$.

S2. Effect of turmeric fraction on joint inflammation. Female Lewis rats were injected on day 0 with SCW $(25 \mu \mathrm{g} / \mathrm{g})$ or vehicle. Joint swelling was assessed by daily calculation of the arthritic index (mean \pm SEM) with statistical significance determined by Students' T test as described in methods. (A) Turmeric fraction $(23 \mathrm{mg} / \mathrm{kg} / \mathrm{d})$ or vehicle alone ip injections were begun 4 days prior to SCW administration $(n=11$ animals/group) and continued on a daily basis until 10 days after SCW injection at which time treatment frequency decreased to 5 days/week. $* \mathrm{p}<0.01$. (B) Turmeric fraction (23 $\mathrm{mg} / \mathrm{kg} / \mathrm{d}$ ) or vehicle alone ip injections were given daily beginning 8 days after SCW administration ( $\mathrm{n}=10-11$ animals/group). ${ }^{*} \mathrm{p}<0.01$. (C) Turmeric fraction $(4 \mathrm{mg} / \mathrm{kg} / \mathrm{d})$ or vehicle alone ip injections were begun 4 days prior to SCW administration $(n=11$ animals/group) and continued on a daily basis until 10 days after SCW injection at which time treatment frequency decreased to 5 days/week. * $\mathrm{p}<0.05$. 
Figure S1

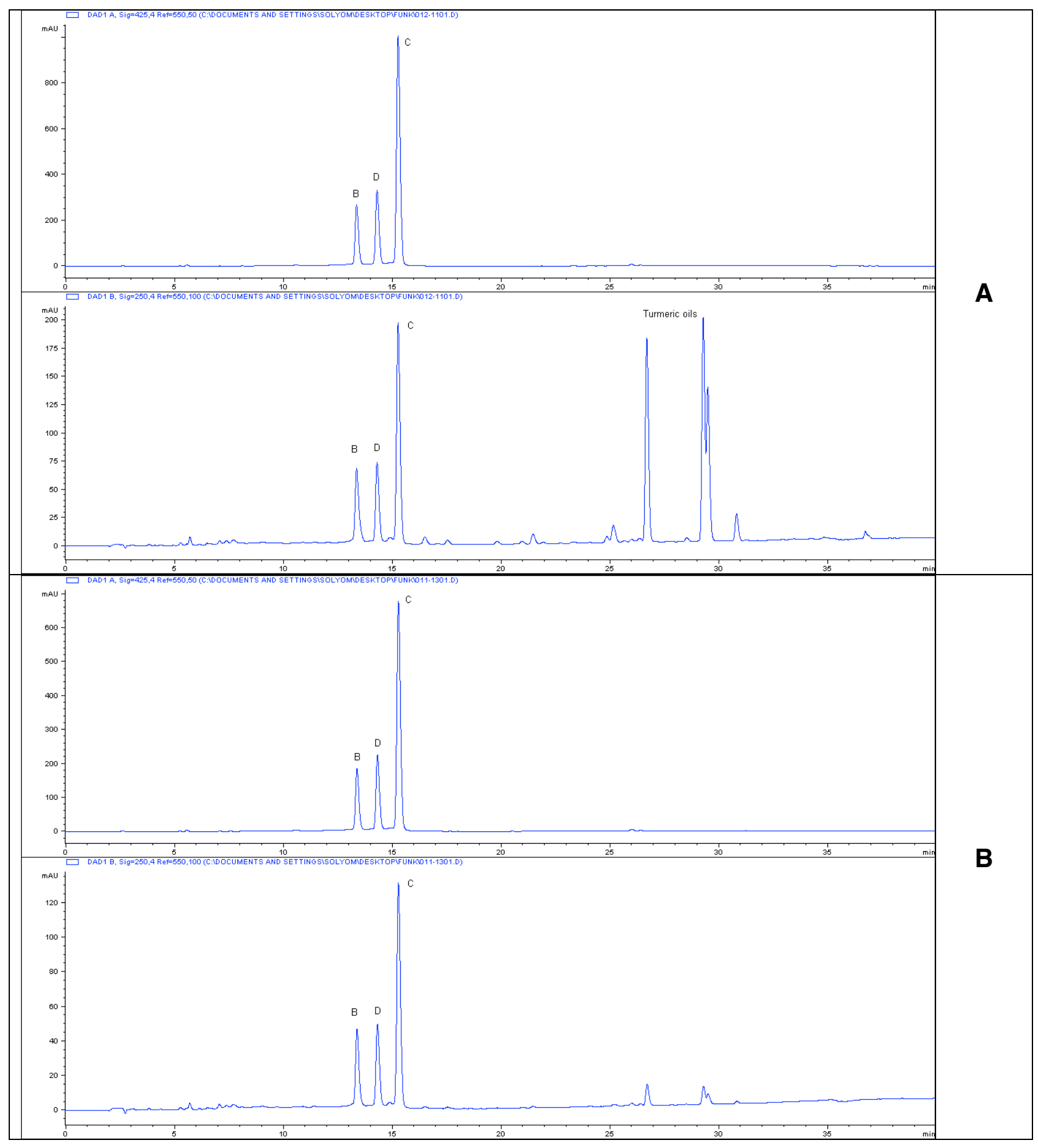




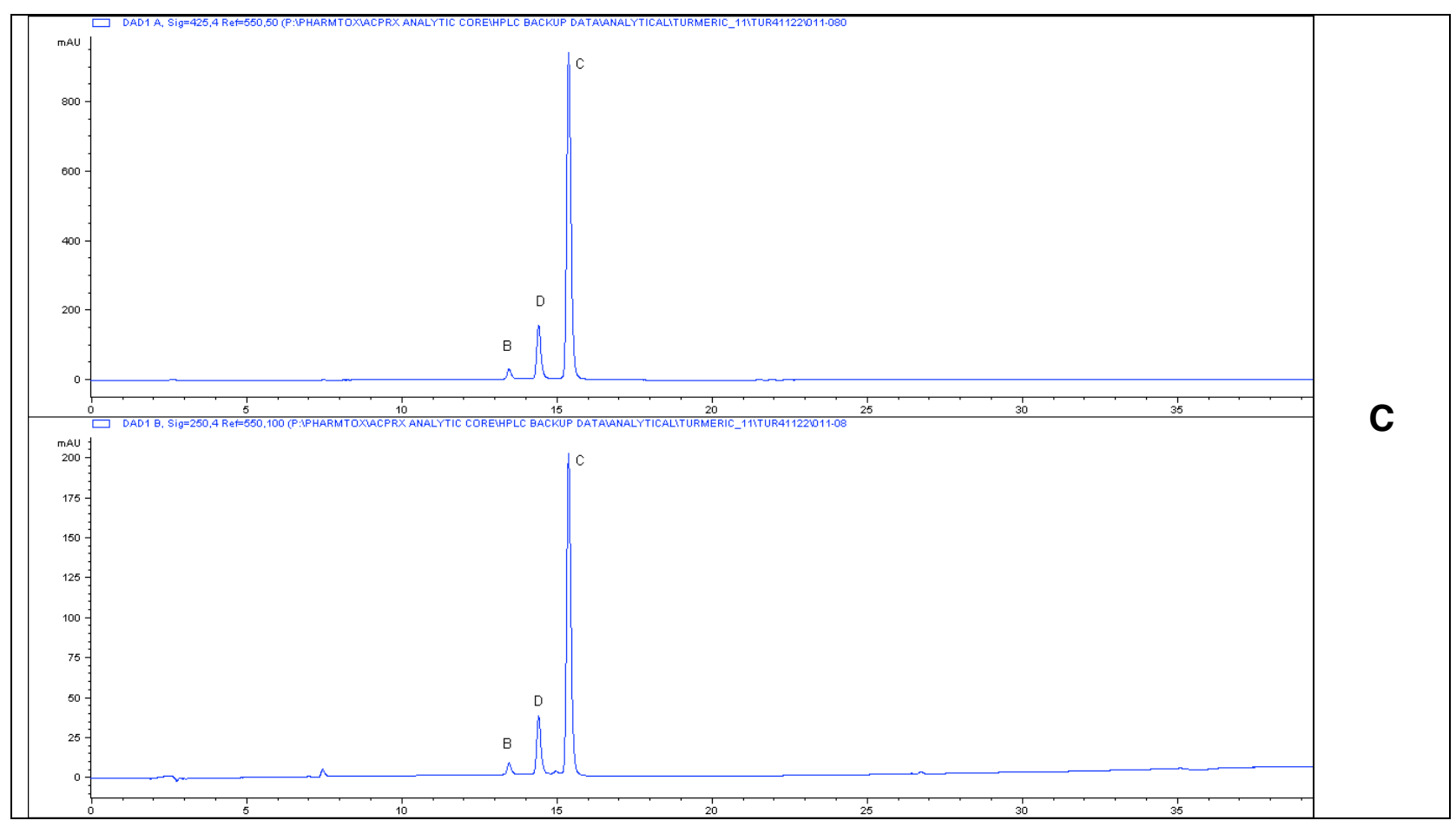


Figure S2A

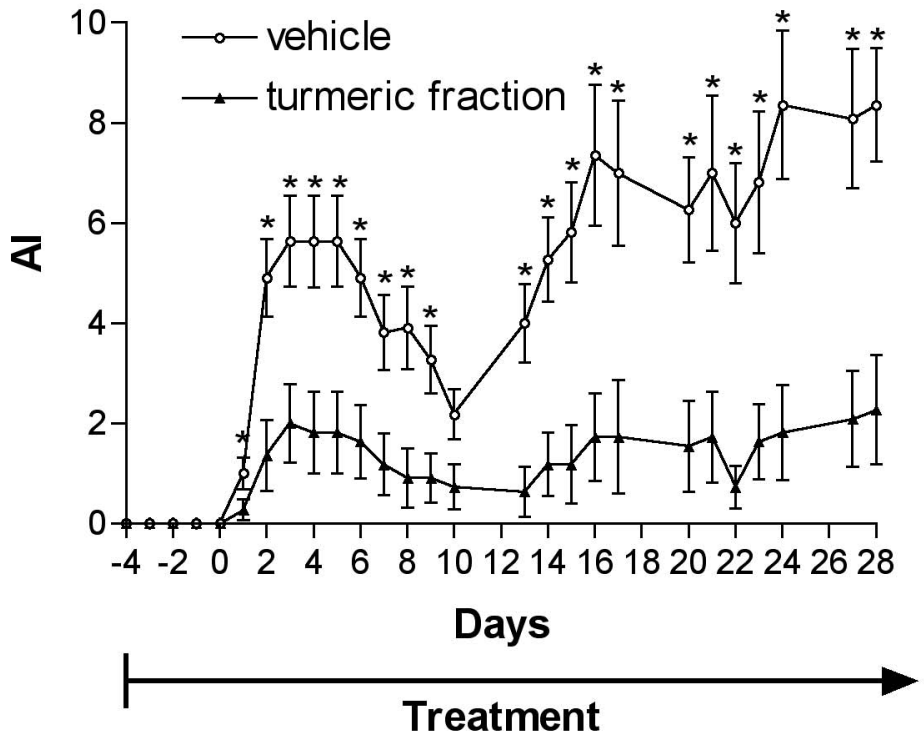


Figure S2B

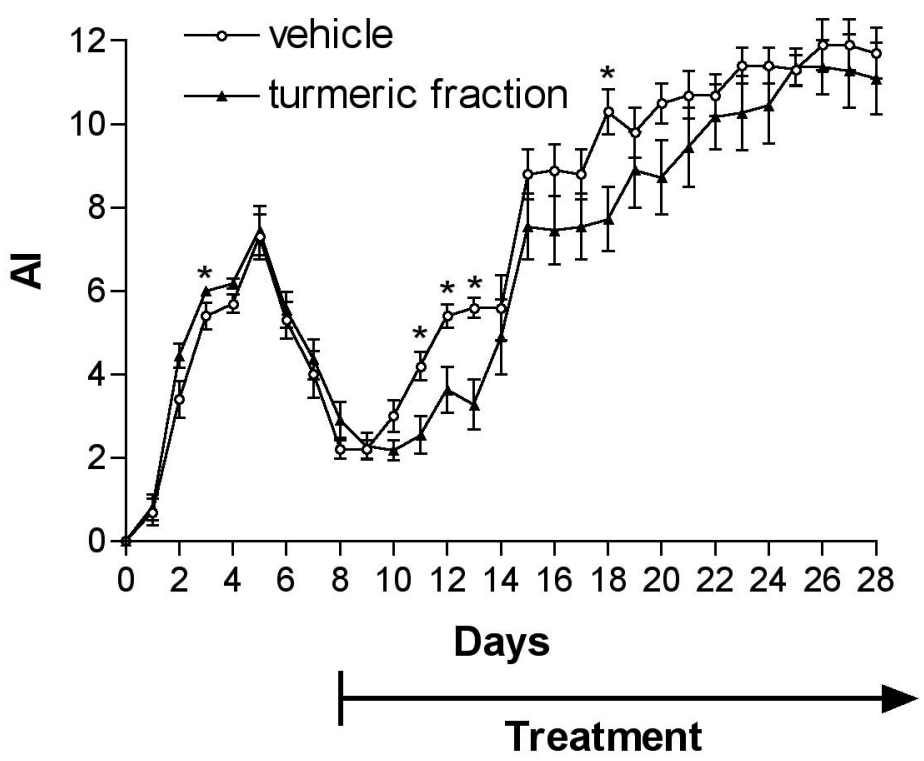


Figure S2C

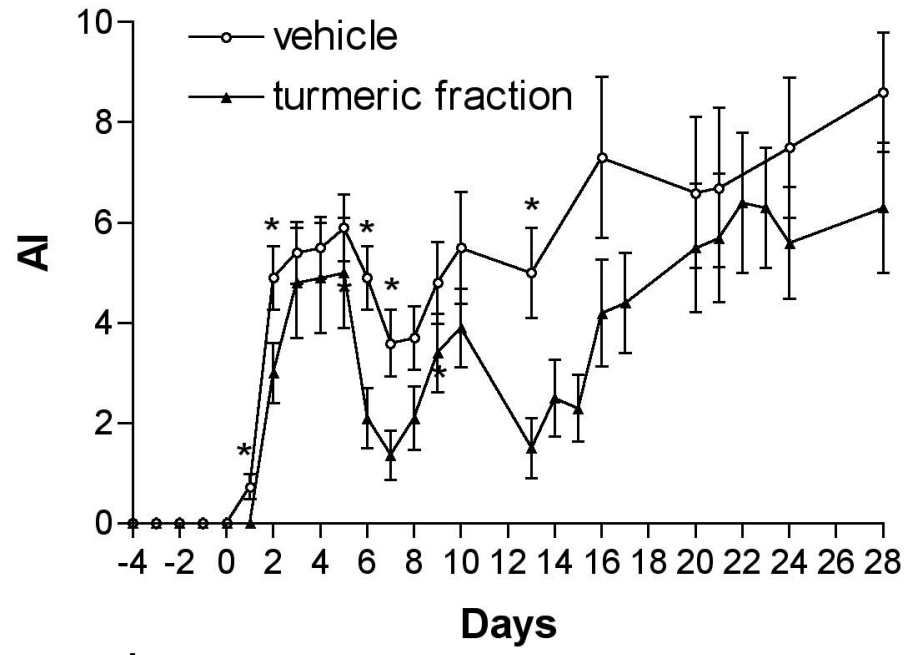

Treatment 